\title{
Pensando possibilidades acerca da formação de professores*
}

Anthony Fábio Torres Santana ${ }^{a}$

\section{Editores}

Maria Inês Côrte Vitoria PUCRS, Brasil Pricila Kohls dos Santos PUCRS, Brasil

\section{Equipe Editorial} Carla Spagnolo PUCRS, RS, Brasil Marcelo Oliveira da Silva PUCRS, RS, Brasil

Rosa Maria Rigo PUCRS, RS, Brasil

ISSN 2179-8435

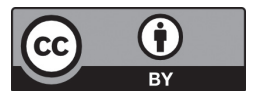

A matéria publicada neste periódico é licenciada sob forma de uma Licença Creative Commons - Atribuição 4.0 Internacional. http://creativecommons.org/licenses/by/4.0/
RESUMO: Este texto percorre caminhos pensando o conceito de formação, bem como busca compreender seus entendimentos na educação. Assim, reflete a formação docente, enquanto movimentos que ensinam e constituem o professor, através das relações da vida, no ensinar e aprender com seus alunos em sala de aula cotidianamente. Os saberes outrora elencados a formação, baseados em ações disciplinares, são frutos de uma modernidade cientificista que estratifica o conhecimento, e o coloca em progressão linear. Tal construção vem nos instituindo como sujeitos e muito especialmente, como professores. Nessa perspectiva, a formação do docente precisa de espaços e acolhimentos, que possibilitem dentre outros elementos, a existência da criação. Tratando-se, portanto, do compartilhamento da experiência singular de cada vida, da possibilidade da composição do processo formativo atravessado por aspectos plurais. $\mathrm{O}$ presente artigo tem como aporte metodológico a pesquisa bibliográfica. Percorrer estas possibilidades, e em especial as que formam o professor, é o que pretende este escrito.

Palavras-chaves: Formação de professores. Educação. Contemporaneidade.

ABSTRACT: This text follows paths considering the concept of training, and seeks to understand their understandings in education. So I think the teacher training, while movements that teach and are the teacher, through the relations of life, in teaching and learning with their students in the classroom daily. The knowledge previously listed training, based on disciplinary actions, are the result of a modernity that stratifies scientistic knowledge, and puts in a linear progression. Such construction comes in instituting as subjects and especially as teachers. From this perspective, teacher training needs spaces and nesting levels, enabling among others, the existence of creation. Since this is so, the sharing of the unique experience of every life, the possibility of the composition of the training process traversed by plural aspects. This article is methodological contribution to literature. Browse these possibilities, especially those that form the teacher, this is what you want written.

Keywords: Teacher Training. Education. Contemporary.

\footnotetext{
*Este trabalho é um recorte da pesquisa que desenvolvi durante o curso de mestrado em educação, intitulada Diversos tons, lugares dissonantes: o movimento estético do ensinar. Em caráter experimental, publiquei parte do mesmo, nos anais do

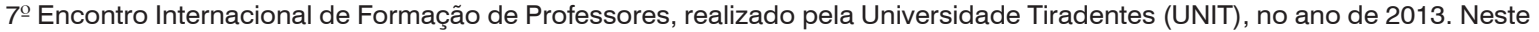
momento, agrego ao manuscrito, problematizações, interpretações e debates diferentes, acerca de determinadas questões que estão compondo o seu tema geral, a saber: a composição do ser professor, a partir de um viés histórico-filosófico.

a'Doutorando em Educação pela Pontifícia Universidade Católica do Rio Grande do Sul (PUCRS). <afabiotorres@ hotmail.com>.
} 
"Compor é juntar notas que se amam."

MOZART

\section{Iniciações: pensando o conceito formação}

Denso que formar-se, requer que nos encontremos abertos às experimentações, para a constituição de si perante o mundo. Assim, quanto mais experimentamos, possivelmente estamos em proporções semelhantes nos colocando disponíveis a entrar em contato com novas experiências. Ao formar-nos, processo infinito de encontros não mensuráveis, estamos tecendo possíveis modos de vida plurais.

Nessa perspectiva podemos pensar também em uma autonomia do sujeito, quando do traçado das linhas compositoras da sua formação, à medida que este tem liberdade por optar, fazer determinadas escolhas que mostre suas predileções quando do percorrer do processo formativo. Reagindo, dessa maneira, às possíveis adaptações, podendo ainda tecer contatos com outros conceitos, diferenciadas bases teóricas e pensamentos.

O conceito de Bildung (formação), transformado pela hermenêutica, implica reconhecer a capacidade de luta do sujeito em se autoeducar, em saber que ele pode reagir para além de todas as adaptações, para além de todos os projetos de sentido que lhes são oferecidos por certos ordenamentos simbólicos e que nunca é totalmente aprendido pelos nossos esquemas conceituais - ou seja, a preservação da dimensão fundamental do conceito clássico de Bildung: a liberdade do indivíduo para determinar seu processo de formação. O que é irrevogável na formação, sua marca e vestígio mais persistente, é a ideia de que a pessoa se constitui a si mesma num vínculo com o mundo, um trabalho feito com 'paciência e suavidade' - algo que a hermenêutica sabe ser próprio da aventura humana. (HERMANN, 2010, p. 120)

O conceito de Bildung (formação) utilizado como referência pela autora Nadja Hermann encontra-se e é desenvolvido ainda na obra "Verdade e Método I - Traços fundamentais de uma hermenêutica filosófica" do Hans-Georg Gadamer (2008), onde este nos fala que: "a formação não deve ser entendida apenas como o processo que realiza a elevação histórica do espírito ao sentido universal, mas é também o elemento onde se move aquele que se formou" (p. 50). Desse modo, o Gadamer nos leva a refletir, para além da perspectiva da elevação do indivíduo quando em contato com o processo formativo, mas igualmente, mostra a formação enquanto um possível campo onde aquele pode se movimentar, tecendo assim encontros e escolhas.

Talvez, caiba nesse momento, pensarmos acerca das relações compostas entre a cultura (saber cultural) e a formação. Será que as questões colocadas através das expressões culturais do nosso tempo, encontram reciprocidade nas ressonâncias da formação presente neste tempo?

Educação Por Escrito, Porto Alegre, v. 5, n. 1, p. 30-40, jan.-jun. 2014 
Comumente ouço pessoas se questionarem sobre os saberes que se ocupam em seus cursos de formações e quais relações estes tecem com o que está acontecendo no agora, em nosso tempo. Trata-se nesse sentido, de buscarmos possíveis problematizações para a formação enquanto processo que se desenvolve na vida, em seus acontecimentos.

Portanto, faz-se importante pensarmos a formação enquanto movimentos, lembrando que dificilmente estamos a nos movimentar sozinhos. "O que interessa reter para a formação é justamente a idéia de um movimento do ser que volta a si mesmo a partir do outro" (HERMANN, 2002, p. 100). Existem sempre ressonâncias de autores lidos, de pessoas com as quais compomos encontros, proporcionando desse modo, a abertura para o reconhecimento da alteridade nessas relações, produzindo assim, sentido ao que nos chega de fora, através do outro. "A formação é assim uma abertura para o reconhecimento da alteridade, fazendo com que sejamos capazes de dar sentido àquilo que vem de fora de nós, o que significa compreender o outro e o saber cultural" (HERMANN, 2002, p. 102).

Possivelmente, não podemos pensar a formação apenas como um objetivo a ser perseguido. Cabe a nós propormos antes, questionamentos acerca desses processos: a que tipo de formações estamos sendo submetidos, bem como disponibilizando aos outros? Formar-se também implica estarmos abertos ao contato com formas de pensamentos diversas. Mas devemos ter cuidado, especialmente em uma contemporaneidade que anseia pela tão falada e almejada formação continuada (docência), assim, vale lembrar: "no fundo, formação não pode ser um objetivo, não pode ser desejada, a não ser na temática reflexiva do educador" (GADAMER, 2008, p. 46).

Deste modo, convido-os agora a refletirmos nas próximas linhas, acerca da formação de professores.

\section{Formação de professores: pela possibilidade de uma ética da reflexão}

Pensar formação, mais especificamente a formação do professor, requer a meu ver acentuada atenção e cautela. Falo isso, por considerar esse um campo tênue, e ao mesmo tempo relevante para a vida de todos aqueles que participam dessa trama.

Penso a formação docente, enquanto movimentos, considerando assim, a produção da subjetividade que ensina e constitui o professor, através das relações da vida, no ensinar e aprender com seus alunos em sala de aula cotidianamente.

Desde quando me pus a pensar o percorrer infinito que é tornar-se professor, incomodavam bastante, algumas discussões que se colocam a refletir a formação docente, apenas em um espectro dual que são os campos da teoria e da prática. Mas, cabe aqui uma pergunta: quais aspectos teóricos e práticos poderiam ser elencados à formação? Possivelmente se enumerar determinadas teorias e outros exercícios práticos, caia em um modelo de formação (do professor) e isso, penso que não nos interessa. 
Esta é uma discussão relativamente antiga, mas que até hoje permeia e gera alguns "estranhamentos" dentro dos espaços acadêmicos. Há os que prefiram pensar a formação docente fundamentando-a apenas em elementos do campo teórico, como também aquelas pessoas que não acreditam que seja possível refletir a formação do professor se não homogeneizando o diálogo entre teoria e prática.

Considerando o amplo debate que se desenvolve na atualidade acerca deste tema, trarei o pesquisador Júlio Emílio Diniz-Pereira, que também se coloca sobre tal problematização, instrumentalizando-se para tanto, do que nos diz a legislação educacional brasileira:

[...] mesmo que a legislação educacional brasileira, no que tange à formação de professores, tenha avançado ao insistir no princípio da indissociabilidade teoria-prática na preparação desses profissionais e, para tal, determinado um aumento significativo da carga horária teórico-prática nas licenciaturas, isso não garante que as nossas instituições de ensino superior seguirão tal princípio e traduzirão em propostas curriculares tal ideia. (DINIZ-PEREIRA, 2011, p. 11)

Como nos aponta o Júlio Emílio, apesar de encontrar-se presente na nossa legislação educacional um avanço significativo na perspectiva de aliar elementos teóricos e práticos na formação dos professores, isso não assegura que as faculdades e/ou universidades do Brasil sigam essa indicativa e exercite tais ações através da composição e aplicação dos seus currículos.

Cogitar um diálogo entre a teoria e a prática na composição da docência, não é sinônimo, nem apresenta qualquer vontade de que um aspecto se sobreponha ao outro no permanente caminhar que é a constituição do ser professor. Dessa forma, entendo salutar ouvir quem tece outras opiniões acerca de como pensar possíveis formações para os nossos professores. Procurando ouvir o que difere do que nos colocamos agora, também é formação.

[...] por mais de um século, advoga-se a favor da prática como fonte de aprendizagens múltiplas sobre a docência. Porém, ainda hoje se observa, principalmente nos meios acadêmicos, uma grande resistência em reconhecer isso e, nas instituições de ensino superior, de se utilizar tal princípio para orientar as reformas dos cursos de formação de professores. É importante enfatizar, todavia, que tal resistência não é necessariamente negativa. Vários grupos progressistas e comprometidos com a questão da formação de professores nas universidades temem que a ênfase na dimensão prática possa reforçar as ideias conservadoras e retrógradas que limitam a formação docente ao mero treinamento de habilidades necessárias ao ensino, ou seja, concepções meramente técnicas e instrumentais sobre a formação de educadores [...] é importante ressaltar que, em função da necessidade urgente de se habilitar aqueles que, hoje, no país, estão em sala de aula, exercendo o magistério, corre-se o risco de as recentes políticas educacionais para formação docente favorecerem a improvisação no preparo dos profissionais da educação. (DINIZ-PEREIRA, 2011, p. 11)

Educação Por Escrito, Porto Alegre, v. 5, n. 1, p. 30-40, jan.-jun. 2014 
$\mathrm{Na}$ contemporaneidade, estamos vivendo uma urgência que é transportada não só do trabalho para casa, como também de casa para as salas de aula, essa urgência parece indissolúvel da vida. De todos os lados somos cobrados a exercitar uma velocidade em nossas ações como ainda não tínhamos visto antes. Assim, nessa mesma velocidade muitas pessoas estão a tornar-se "professores", e talvez você se pergunte, como, tornando-se professores?

Não muito raro é divulgado na televisão, ou mesmo em outdoors pelas avenidas, anúncios que falam assim: "venha fazer seu curso superior em dois anos, estudando apenas nos finais de semana". Percebo também que vários dos cursos que ali são ofertados tangem as áreas de formação, em sua maioria licenciaturas. E aqui eu respondo, é dessa forma que muitos sujeitos estão a "tornarem-se professores", cursando licenciaturas no período de dois anos, aos fins de semana.

Anteriormente, me reportei ao ensino superior privado, mas acontece também, que temos ações sendo desenvolvidas através de políticas educacionais ligadas ao estado, visando à formação superior daqueles professores que há bastante tempo atuam no magistério, sem muitas vezes pensarem acerca da formação que estão propiciando a estes docentes, Diniz igualmente nos alerta sobre tal fato.

Em nome dessa urgência, a prática, que deve ocupar um espaço significativo nas grades curriculares dos cursos de licenciatura, pode ser compreendida erroneamente como formação em serviço. As horas trabalhadas em sala de aula, sem, necessariamente, um planejamento e uma intencionalidade formativa, podem, assim, ser contabilizadas nos novos cursos de licenciatura pelos profissionais já em exercício na escola. Como consequência, diminui, significativamente, a carga horária dos cursos de formação inicial de professores, o que, obviamente, não é desejável e representa um imenso retrocesso em termos da preparação desses profissionais. (DINIZ-PEREIRA, 2011, p. 15)

Essa urgência possivelmente tende a fragilizar significativamente os cursos de formações pelos quais passam as pessoas que, em um futuro não muito distante, estarão tendo em suas mãos a responsabilidade de formar outros "tantos" cidadãos, que por circunstâncias diversas possam vir habitar suas salas de aulas, isto é, se já não estiverem habitando, pois não raramente encontramos estudantes em nossas turmas que por sua vez, igualmente atuam como docentes.

O que mais me põe inquieto é perceber em determinados casos, que nós mesmos, professores, por vezes não questionamos essas iniciativas. É como se criassem mutirões para formar docentes. Assim, modificam-se currículos, alteram-se linhas teóricas dos cursos, mas não com a mesma frequência discute-se sobre essas atitudes e ainda menos acerca da qualidade dos cursos oferecidos aos também já professores. 
[...] o descuido com o embasamento teórico na formação de professores, indispensável no preparo desse profissional, é extremamente prejudicial aos cursos de licenciatura. O rompimento com o modelo que prioriza a teoria em detrimento da prática não pode significar a adoção de esquemas que supervalorizem a prática e minimizem o papel da formação teórica. Assim como não basta o domínio de conteúdos específicos e/ou pedagógicos para alguém se tornar um bom professor, também não é suficiente estar em contato apenas com a prática para se garantir uma formação docente de qualidade. Sabe-se que a prática pedagógica não é isenta de conhecimentos teóricos e que estes, por sua vez, ganham novos significados quando diante da realidade escolar. (DINIZ-PEREIRA, 2011, p. 15)

Mas qual o perfil dessas pessoas que ingressam nos cursos de formação de professores no Brasil? Segundo Diniz-Pereira: “[...] em grande parte dos cursos de licenciatura ingressaram muitos estudantes provenientes da rede pública de ensino, que frequentaram cursos noturnos, não fizeram 'cursinhos' e tinham pais com escolaridade inferior ao ensino médio completo" (DINIZ-PEREIRA, 2011, p. 41).

Tendo em mãos esses dados, talvez seja preciso refletir ainda mais acerca da importância de problematizarmos os componentes que direta ou indiretamente estão compondo a formação dos nossos professores. Penso que não podemos nos munir apenas de um discurso confortável e proclamar acesso à formação continuada, sem antes nos debruçarmos sobre quem são esses professores, quais suas realidades, e também, quais formações disponibilizar a eles.

É nessa perspectiva que aceno para a possibilidade da existência de uma ética ${ }^{1}$ da reflexão nos processos de formação de professores, uma vez que formar-se, requer que nos encontremos abertos às experimentações, para a constituição de si perante o mundo. Igualmente penso que não podemos nos separar do poder que existe no questionamento e na reflexão, acerca dos elementos que nos são propostos e escolhemos para nos compor enquanto docentes.

O próximo passo deste escrito é olhar para o cada vez mais crescente desprestígio social do docente na contemporaneidade.

\section{A (des)potencialização do professor na contemporaneidade: pela (im)possibilidade de um final}

Esse mesmo tempo acelerado que apresenta a possibilidade de uma formação em licenciaturas de dois anos, com aulas somente aos fins de semana, carrega consigo um índice não revelado naquelas propagandas de universidades

1 Lembrando que: “[...] a ética diz respeito a um modo de vida, a um estilo de existência” (KOHAN, 2007, p. 2). 
anteriormente citadas. Aqui me refiro ao desprestígio social do professor. Desprestígio esse que, segundo Durval Muniz, chegou antes mesmo da perda de credibilidade da instituição escolar, hoje também já visualizada por alguns de nós.

O desprestígio social do professor, da profissão docente, talvez tenha antecedido o próprio desprestígio social da escola, do ensino escolar, talvez tenha sido um dos primeiros indícios de que a instituição escolar já não gozava da irrestrita legitimidade social que ainda se acreditava possuir. Este desprestígio social do professor não se materializa, apenas, na redução progressiva de sua remuneração, em todos os níveis de ensino, mas no próprio desprestígio da profissão, na perda de status, de valor simbólico da profissão na vida social. (ALBUQUERQUE JÚNIOR, [s/d], p. 2)

Quando reflito sobre o, cada vez mais acentuado desprestígio social do professor, não penso exclusivamente na excessiva carga-horária de trabalho a qual esse é submetido comumente, a duras penas de não obter salários que se mostrem equivalentes ao esforço e tempo disponibilizado em suas ações, o que consequentemente acarreta na necessidade desse sujeito (professor) ter que buscar em sua maioria quase que absoluta o vínculo empregatício com várias instituições.

$\mathrm{O}$ que acabei de relatar compromete diretamente a formação dos nossos professores e alunos. Existem casos de docentes que falam abertamente que queriam buscar outras formas de pensar para trazer aos seus discentes, mas que são impedidos pela escassez de tempo. Acrescentam que tal ação torna-se humanamente impossível, à medida que estes se sentem obrigados a ter dois ou mais empregos para possibilitarem uma vida digna aos seus familiares.

Nessas mesmas conversas faço questão de propor pensarmos acerca da escolha que é a de querer tornar-se docente, parte fundamental da composição do ser professor. Por ter tido contato com alguns discursos historicamente firmados ainda muito cedo, a exemplo do da desvalorização do trabalho, da falta de reconhecimento. Essa relação fez também com que tivesse ainda mais certeza do caminho que ia trilhar e que não me colocasse em um posicionamento fixado à propagação dessas falas, em detrimento ao compromisso com a minha formação e com a dos meus alunos.

O desprestígio do professor passa antes, em minha opinião, pela própria depreciação da profissão docente tecida em nossa sociedade, como também pela qualidade da formação que está sendo disponibilizada a esses professores. Fato que tem levado muitas pessoas a pensarem erradamente que, profissionais de quaisquer áreas possam exercer nossas funções, já que em determinados casos, não é tarefa difícil perceber o despreparo daqueles que se expõem ao exercício do magistério. 
Neste aspecto nossos cursos universitários de Licenciatura podem ser chamados de fábricas de celacantos, porque formam professores já completamente obsoletos, professores para uma sociedade que não existe mais, para uma escola que só os admite porque é mais atrasada do que eles próprios. Este círculo vicioso está pondo fim à escola e à profissão docente. Licenciandos que já são educados de forma obsoleta, ao chegarem às escolas constatam desiludidos e desestimulados que são muito inovadores e criativos para a escola que encontram. A tendência é que rapidamente incorporem a cultura escolar, esqueçam os modelos moderninhos que aprenderam nas aulas de Prática de Ensino e se conformem às demandas e regras desta cultura escolar rotineira e que tem pouco lugar para o professor contestador ou inovador. A maneira como os professores de história utilizam os livros didáticos é um exemplo significativo disto. Após ouvirem durante sua graduação inúmeras críticas ao uso do livro didático como material único e exclusivo para o ensino da história, ao chegarem às escolas, pressionados pela cultura escolar que consagra o livro didático como o único e principal recurso didático a ser usado, passam a reproduzir esta atitude, até porque ela é mais fácil, ela evita maior trabalho, para um profissional já normalmente sobrecarregado por diversos turnos de trabalho. (ALBUQUERQUE JÚNIOR, [s/d], p. 11-12)

Voltando-se à história veremos que a educação brasileira em décadas passadas mostrava-se privilégio de grupos abastados, excluindo através do gênero, da etnia e das classes, uma parcela significativa da sociedade. Reafirmando nesse movimento a carreira do professor, enquanto uma profissão diretamente ligada a um prestigiado grupo social, já que esse era responsável pela formação das referidas elites. Vejamos o perfil das nossas escolas naquela época, o espaço de atuação do docente, onde ele, em uma ação mútua, não apenas forma, como também se compõe (forma-se/ torna-se) professor.

No Brasil, uma sociedade profundamente hierárquica e excludente, a escola foi, durante muito tempo, um privilégio de classe, de etnia e de gênero. A escola estava destinada à formação de uma dada elite que se dizia branca, notadamente dos homens filhos destas elites. Pensar que só a partir dos anos cinquenta do século XX, que o ensino começa a se massificar no Brasil, a chegar à zona rural, outra realidade comumente excluída, a ser acessível às mulheres, a dar acesso às camadas médias e alguns elementos da raça negra, que ainda lutam hoje em dia por pleno acesso a ela, dá a medida do caráter excludente desta escola. (ALBUQUERQUE JÚNIOR,[s/d], p. 5)

A instituição escolar moderna também exclui a partir das ações daqueles que a compõe: gestores, secretárias, professores... A formação lançada pela escola dialoga com dispositivos disciplinares, fazendo ecoar nas linhas do tempo, na tecitura das sociedades que gestam ao formar, seu caráter conservador. 
Esse modelo de escola tornou possível o mercado capitalista nascente e a solidez das ciências positivas, a partir da produção de signos, conceitos, valores morais e culturais que propagou e ainda dissemina. A escola reafirmou as revoluções que a Modernidade gestou: a Revolução Industrial no campo econômico e a criação de um mercado que necessitou de uma mão de obra disciplinada para a produção; a Revolução Francesa no campo político que instaurou a democracia burguesa e com ela a ideário de uma escola para todos; o Iluminismo no campo das ideias, que passou a inaugurar uma razão científica positivista propagada pela escola em seus currículos e conteúdos programáticos, e o Renascimento, que com seus valores estéticos e artísticos estabeleceu a dicotomia entre a cultura erudita e a cultura popular.

A instituição escolar é, pois, uma criação da Modernidade, que a burguesia foi direcionando a seu favor. E embora mais tarde tenha adquirido o sentido de escola pública, a promessa de formação integral foi limitada aos interesses políticos e econômicos, demarcando conteúdos e saberes. Os avanços no sentido de criação de um ensino público revigoraram os projetos disciplinares e moralizantes, em nome do desenvolvimento universal do progresso. valores da ordem burguesa que se tornava vitoriosa. A educação é pensada como formação, desde pelo menos o final do século XIX, substituindo a educação pensada como instrução, como mero acúmulo de saberes, como a memorização e aquisição de uma grande quantidade de informações, como erudição, que será criticada por não atender imediatamente o interesse social e se concentrar na dimensão intelectual da educação negligenciando aspectos como a educação física ou a educação técnica, voltada para o trabalho. (ALBUQUERQUE JÚNIOR, [s/d], p. 9)

A educação escolarizada e pública sintetiza, de certa forma, as ideias e os ideais da Modernidade e do Iluminismo. Ela corporifica o pensamento de progresso constante através da razão e da ciência, de crença nas potencialidades e desenvolvimento de um "sujeito" autônomo e livre, de universalismo, de emancipação política e social, de ampliação do espaço público através da cidadania, de nivelamento dos privilégios hereditários, e de mobilidade social.

A escola está no centro dos ideais de justiça, igualdade e distributividade do projeto moderno de sociedade e política. Ela não apenas resume estes princípios, propósitos e impulsos: ela é a instituição encarregada de transmitilos, de torná-los generalizados. "[...] a escola pública se confunde, assim, com o próprio projeto da modernidade. Ela é a instituição moderna por excelência" (SILVA, 2000, p. 214).

A partir da segundo metade do século XX, essa concepção de escola passa por uma crise, atribuída à própria falência das instituições modernas. A missão civilizadora de promover modelos culturais e os esforços de racionalizar 
pessoas para administrar o mundo, perde a sua força. Os dispositivos de poder disciplinares, tão úteis em outras épocas da sociedade, começam a alterarem-se, assim, a instituição escolar começa a nos dar sinais do seu desfalecimento.

Tal construção vem nos instituindo como sujeitos e muito especialmente, como professores. Os saberes outrora elencados a formação, baseados em ações disciplinares, são frutos de uma modernidade cientificista e linearizada que estratifica o conhecimento, coloca-os em segmentos e progressão linear, despossibilitando a compreensão do pensamento.

Nessa perspectiva, a formação do professor precisa de espaços e acolhimentos diversos, que possibilitem a existência da criação. Trata-se do compartilhamento da experiência singular de cada vida, das ações desenvolvidas especialmente a partir das relações tecidas entre professores, e alunos.

A formação docente assim entendida pode ser pensada a partir da máxima grega: "Converte-te no que tu és". Converter-se no que se é, é procurar expandir as singularidades e as diferenças que produzem a vida do professor. Significa vencer-se, superar-se, pois, como nos aponta Nietzsche: "Nós, que somos homens do conhecimento, não conhecemos a nós próprios; somos de nós mesmos desconhecidos [...]" (2009, PRÓLOGO).

Deste modo, penso que, para se constituir docente tem-se que ir além das formações didáticas e pedagógicas, e caçar-se a si mesmo. Tornar-se professor, passa antes, pela composição de um percurso contínuo, de inusitados movimentos e encontros. Colocando-se, portanto, num plano de multiplicidades e diferenças acima e além de onde estejam seus próprios pés.

\section{Referências}

ALBUQUERQUE JÚNIOR, Durval Muniz de. Por um ensino que deforme: o docente na pós-modernidade. Disponível em: < http:// www.cnslpb.com.br/arquivosdoc/MATPROF.pdf >. Acesso em: 17 mar. 2014.

DINIZ-PEREIRA, Júlio Emílio. O ovo ou a galinha: a crise da profissão docente e a aparente falta de perspectiva para a educação brasileira. Revista Brasileira de Estudos Pedagógicos, v. 92, p. 34-51, 2011.

DINIZ-PEREIRA, Júlio Emílio. A prática como componente curricular na formação de professores. Educação (UFSM), v. 36, p. 203-218, 2011.

GADAMER, Hans-Georg. Verdade e Método I: traços fundamentais de uma hermenêutica filosófica. Tradução de Flávio Paulo Meurer. Petrópolis, RJ: Vozes, 2008.

HERMANN. Nadja Mara Amilibia. Autocriação e horizonte comum: ensaios sobre educação ético-estética. Ijuí: Ed. Unijuí, 2010. HERMANN. Nadja Mara Amilibia. Hermenêutica e educação: o que você precisa saber sobre. Rio de Janeiro: DP\&A, 2002.

KOHAN, Walter. Omar. O que pode um professor? Revista Educação - Dossiê Deleuze pensa a educação, São Paulo: Segmento, ano I, ed. esp., p. 48-57, 2007.

Educação Por Escrito, Porto Alegre, v. 5, n. 1, p. 30-40, jan.-jun. 2014 
NIETZSCHE, Friedrich. Assim falava Zaratustra: um livro para todos e para ninguém. Tradução de Mário Ferreira dos Santos. Petrópolis: Vozes, 2007. (Coleção Textos filosóficos).

NIETZSCHE, Friedrich. Genealogia da moral: uma polêmica. São Paulo: Companhia das Letras, 2009.

NIETZSCHE, Friedrich. Ecce Homo: como alguém se torna o que é. São Paulo: Companhia das Letras, 2008.

SILVA, Thomas Tadeu da. O projeto educacional moderno: identidade terminal? In: VEIGA-NETO. A crítica pós-estruturalista e educação. Porto Alegre: Sulina, 2000.

\section{Endereço para correspondência:}

Anthony Fábio Torres Santana

Rua Guilherme Alves, 801, apto. 405 - Jardim Botânico

90680-001 Porto Alegre, RS, Brasil

E-mail:<afabiotorres@hotmail.com>

Recebido em: abril/2014

Aceito em: maio/2014 